\title{
Overview of Anemia among Systemic Lupus Erythematosus Patients in Reproductive Age Women based on Reticulocyte Hemoglobin Equivalent (RET-He) Level and Reticulocyte Count
}

\author{
Ismiana Fatimah Modjaningrat ${ }^{1}$, Amaylia Oehadian², Mohammad Ghozali , Laniyati Hamijoyo²
}

${ }^{1}$ Faculty of Medicine

Universitas

Padjadjaran, Bandung, Indonesia

${ }^{2}$ Department of Internal Medicine, Faculty of Medicine, Universitas Padjadjaran/ Dr. Hasan Sadikin General Hospital, Bandung, Indonesia

${ }^{3}$ Department of Biochemistry and Molecular Biology, Faculty of Medicine, Universitas Padjadjaran, Bandung, Indonesia

Corespondence: Ismiana Fatimah Modjaningat, MD Jalan Raya BandungSumedang Km. 21 Jatinangor, Sumedang Email:

miamodjaningrat@ gmail.com

\begin{abstract}
Background: Anemia is a common manifestation found among patients with Systemic Lupus Erythematosus (SLE). It may be caused by iron-deficiency, autoimmune hemolytic, and chronic inflammation. Each anemia has different therapy approachments. Without adequate management, anemia may lead to poor prognosis. By identifying the etiology of anemia, appropriate management could be conducted. Reticulocyte Hemoglobin Equivalent (RET-He) and reticulocyte count test may distinguish anemia based on its etiology. This study aimed to give scientific portrayed of the proportion of anemia based on its etiology among patients with SLE using RET-He and reticulocyte count.
\end{abstract}

Method: This study involved women diagnosed with SLE underwent outpatient treatment in Rheumatology Clinic, Dr. Hasan Sadikin General Hospital during SeptemberOctober 2016. Data were collected from blood exam using 35-parameters hematology Sysmex by calculating levels of hemoglobin, RET-He, and reticulocyte count. Results: Seventy four female patients were volunteered as subject in this study with median of age was 29.5 (16-70) years old. Thirty four (46\%) of 74 subjects were suffering from anemia and 12 (35\%) of them were between 25-34 years old. Proportion of iron-deficiency anemia, autoimmune hemolytic anemia, and chronic inflammatory anemia were 14 ( 41\%), 13 (38\%), and 7 $(21 \%)$, respectively.

Conclusion: Based on hemoglobin, RET-He, and reticulocyte count, iron-deficiency anemia is the most common anemia among patients with SLE in repoductive age.

Keyword: Age, Anemia, Reticulocyte, RET-He, Systemic Lupus Erythematosus (SLE)

\section{Introduction}

Anemia is the most common hematology complication among Systemic Lupus Erythematosus (SLE) patients, with prevalence of $59 \% .^{1}$ This complication may raise morbidity and mortality of SLE patients It will reduce patient's life quality, if it is not treated appropriately. ${ }^{2}$ Renal failure, serositis, and seizure are several complication presented in that circumstances. ${ }^{3}$ It rise the urgency to detect the etiology of anemia among SLE patients. So appropriate treatment would be given according to etiology.

Etiology of anemia among SLE patients may vary such as iron deficiency, autoimmune hemolytic, and chronic inflammatory ${ }^{4}$ iron deficiency anaemia (IDA Each anemia has different approach to treat. Previous study stated that anemia among SLE were commonly found on particular age range of 15-29 years old, ${ }^{5}$ thus approach of anemia etiology according to age may assist in managing therapy.

The requirement of iron among reproductiveaged women is also risen due to menstruation and preparation for pregnancy. Pregnant women suffered from anemia have higher level of morbidity and mortality ${ }^{6}$. Besides, anemia will also affect fetal development. ${ }^{7}$ Therefore, early detection of anemia among reproductive-aged women is important.

In 2005 similar study to portray proportion of each anemia in patients with SLE was conducted using ferritin as the parameter. Ferritin level in patient with SLE is likely to increase due to inflammation. ${ }^{8}$ Therefore, the study revealed bias results. Method to detect etiology of anemia by measuring level of hemoglobin in reticulocyte (RET-He) is suggested to be more efficient and cheaper. ${ }^{9}$ This parameter easily distinguish irondeficiency anemia accurately with a sensitivity of $93.3 \%$ and a specificity of $83.2 \% .^{9}$ On the other side, reticulocyte count may be used as reference to differentiate autoimmune hemolytic anemia, ${ }^{10}$ thus by combining both parameters, the etiology of anemia among SLE patients may be identified.

In this study, we applied combination of hemoglobin level measurement, RET-He, and reticulocyte count among SLE patients, and try to find each proportion anemia based on its etiology.

\section{Method}

This descriptive study with cross-sectional design and consecutive sampling method had been done 
to 74 women diagnosed with SLE visited Rheumatology Clinic, Dr. Hasan Sadikin General Hospital Bandung during September to October 2016. This study had been approved by hospital ethical committee of Dr. Hasan Sadikin General Hospital.

Systemic Lupus Erythematosus patients with ongoing bleeding include menstruation period or infection and SLE patients who had received packed red cell blood transfusion in the prior three months were excluded from this study. Blood samples were taken at laboratory of Clinical Pathology Dr. Hasan Sadikin General Hospital with patient's consent. Blood test included hemoglobin level, RET-He level, and reticulocyte count, were performed using Sysmex XN 1000. The machine uses principles of flow cytometry, where blood sample will be converted into a fluorescent-labeled suspension and then inserted into a narrow gap, and was shot by some rays. ${ }^{11}$

Patients were classified as anemia if hemoglobin level was $<12 \mathrm{gr} / \mathrm{dL}$. For etiology classification, we referred to RET-He level and reticulocyte count. RET-He level $<27.2 \mathrm{pg}$ showed iron deficiency anemia and reticulocyte count $>1.5 \%$ showed autoimmune hemolytic anemia, while in chronic inflammatory anemia RET-He level $\geq 27.2 \mathrm{pg}$ and reticulocyte count $\leq 1.5 \% .^{9,10}$ Results in this study were processed by using software in the computer.

Table 1. Classification of Anemia

\begin{tabular}{lcc}
\hline \multicolumn{1}{c}{ Type of Anemia } & RET-He & $\begin{array}{c}\text { Reticulocyte } \\
\text { Count }\end{array}$ \\
\hline Iron Deficiency Anemia & $<27.2 \mathrm{pg}$ & $\leq 1.5 \%$ \\
Chronic Inflammatory Anemia & $\geq 27.2 \mathrm{pg}$ & $\leq 1.5 \%$ \\
Autoimmune Hemolytic Anemia & $\geq 27.2 \mathrm{pg}$ & $>1.5 \%$ \\
\hline
\end{tabular}

\section{Results}

SLE patients most commonly found between 25-34 years old. Thirty four $(46 \%)$ of 74 subjects were suffered anemia. Subjects' age were not well-distributed, and it was known that the median was 29.5 (16-70) years old. Characteristic of subjects were presented in table 2 .

Table 2. Characteristic of Subjects

\begin{tabular}{lc}
\hline Variable & Result \\
\hline Hemoglobin (g/dL) & $12.15(6-16)^{*}$ \\
Age (years old) & $29.5(16-70)^{*}$ \\
$15-24, \mathrm{~N}(\%)$ & $19(26 \%)$ \\
$25-34, \mathrm{~N}(\%)$ & $29(39 \%)$ \\
$35-44, \mathrm{~N}(\%)$ & $17(23 \%)$ \\
$45-54, \mathrm{~N}(\%)$ & $8(11 \%)$ \\
$55-64, \mathrm{~N}(\%)$ & $0(0 \%)$ \\
$65-74, \mathrm{~N}(\%)$ & $1(1 \%)$ \\
Patients with anemia, N(\%) & $34(46 \%)$ \\
Hemoglobin (g/dL) & $9.95(5.6-11.5)^{*}$ \\
RET-He (pg) & $26.98 \pm 5.37$ \\
Jumlah Retikulosit (\%) & $1.86(0.34-11.25)$ \\
\hline
\end{tabular}

*:Not normally distributed data

There were 3 subjects with RET-He $<27.2 \mathrm{pg}$ and reticulocyte count $>1.5 \%$ which were included into iron deficiency anemia cases. Proportion of Anemia based on its etiology and the results of the blood tests in non-anemic subjects were presented in table 3 .

Table 3. Proportion of Anemic and Non-Anemic SLE Patients

\begin{tabular}{ccccc}
\hline & $\begin{array}{c}\text { Iron } \\
\text { deficiency anemia } \\
(\mathbf{1 4} \text { patients, 19\% *) }\end{array}$ & $\begin{array}{c}\text { Autoimmune } \\
\text { hemolytic anemia } \\
(\mathbf{1 3} \text { patients, 18\%) }\end{array}$ & $\begin{array}{c}\text { Chronic } \\
\text { inflammatory anemia } \\
\text { (7 patients, 9\%) }\end{array}$ & $\begin{array}{c}\text { No anemia } \\
\text { (40 patients, 54\%) }\end{array}$ \\
\hline $\mathrm{Hb}(\mathrm{g} / \mathrm{dL})$ & $9.95(5.7-11.7)$ & $9.78 \pm 1.57$ & $9.29 \pm 1.95$ & $13(12-15.8)$ \\
$\mathrm{RET}-$ he (pg) & $21.74 \pm 3.24$ & $31.69 \pm 3.10$ & $28.71 \pm 1.16$ & $31.2(24.9-38)$ \\
Reticulocyte count (\%) & $1.88(0.34-11.25)$ & $2.02(1.51-10.58)$ & $0.91 \pm 0.33$ & $1.68 \pm 0.51$ \\
Age (years old) & $32.86 \pm 10.79$ & $28.85 \pm 9.48$ & $28.29 \pm 8.42$ & $31(16-70)$ \\
$15-24$ & $4(28 \%)$ & $4(31 \%)$ & $3(44 \%)$ & $8(20 \%)$ \\
$25-34$ & $4(28 \%)$ & $6(46 \%)$ & $2(28 \%)$ & $17(43 \%)$ \\
$35-44$ & $3(22 \%)$ & $3(23 \%)$ & $2(28 \%)$ & $9(22 \%)$ \\
$45-54$ & $3(22 \%)$ & 0 & 0 & $5(12 \%)$ \\
$55-64$ & 0 & 0 & 0 & 0 \\
$65-74$ & 0 & 0 & 0 & $1(3)$ \\
\hline
\end{tabular}




\section{Discussion}

Proportion of anemia in this study was not different from previous study in Dr. Hasan Sadikin General Hospital Bandung in 2005, stated that proportion of anemia in SLE patients was $48 \%{ }^{12}$ It is also in line with study stated that SLE patients had suffered from hematology disorder, 50\% of them were anemia. ${ }^{13}$ Proportion of each anemia in this study were different with last study in Dr. Hasan Sadikin General Hospital Bandung on 2005, in which there were no iron deficiency anemia, $8 \%$ of autoimmune hemolysis anemia, and $92 \%$ of chronic inflammatory anemia. ${ }^{12}$ The differences may be caused by different parameter used. In previous study, parameter ferritin were used to portray iron reserved in the body. Unfortunately this parameter is likely to increase in patient with SLE with inflammation so it tends to be misdiagnosed of chronic inflammatory anemia. Therefore in this study, more recent parameters, which are RET-He and reticulocyte count were used.

RET-He or Reticulocyte Hemoglobin Equivalent is a parameter calculating means of hemoglobin level in reticulocyte. It capables to detect iron availability used in erythropoiesis process. Normal limit for RET-He is 27.2 pg, means the amount of iron is available for performing erythropoesis, with sensitivity $93.3 \%$ and specificity $83.2 \%$. $^{9}$

Erythropoiesis process starts from pronormoblast, basophilic normoblast, polychromatophlic normoblast, orthochromatophylic normoblast, reticulocyte, and erythrocyte. During the basophilic normoblast phase, hemoglobin formation is initiated and the process requires iron continuously. ${ }^{10}$ The process of hemoglobin formation is starting from reticulocyte phase and stop when red blood cells have became matured erythrocytes. ${ }^{10}$ In case when iron availability is depleted, hemoglobin formation process will disturb. This will lead the lack of hemoglobin level in immature red blood cells. ${ }^{9}$ Therefore in iron deficiency anemia the RET-He level is decreased.

Level of RET-He among patients with anemia was lowest on patient aged between 45-54 years old, because subjects are not been in reproductive period anymore. Low iron level during menopause is usually caused by iron malabsorption and chronic gastrointestinal bleeding. ${ }^{14}$

In the study conducted in 2014, RET-He was used as parameter to evaluate anemia in patients with cancer and it was concluded that $32 \mathrm{pg}$ was a cut-off point to eliminate iron deficiency with negative predictive value of $98.5 \%$ and $100 \% .{ }^{15}$ Other study in 2013 also used RET-He as a parameter to analyze iron deficiency in geriatric patients and it was concluded that cut off value of $26 \mathrm{pg}$ was able to distinguished iron deficiency anemia with chronic inflammatory anemia with sensitivity of $85 \%$ and specificity of $69 \% .^{16}$

Level of reticulocyte in iron deficiency anemia might be normal, which is ranged between $0.5-1.5 \% .{ }^{10}$ In several subjects with low RET-He level and reticulocyte of $>1.5 \%$ and in nonanemic patients the median of reticulocyte count was high, it might be cause by iron supplementation. Iron supplementation therapy will raise reticulocyte count quickly. ${ }^{17}$

In patients with autoimmune hemolytic anemia, level of RET-He are expectedly to be normal since no iron absorption disturbance happened during erythropoiesis. In autoimmune hemolytic anemia, antibody is not able to distinguish external and self-antigen, thus antibody attacks erythrocyte antigen. ${ }^{10}$ The destruction of erythrocyte is compensated by the rise of erythropoiesis, marked by the raise of reticulocyte count. ${ }^{10}$

Chronic inflammatory anemia is caused by a long-term cytokine production. Cytokine IL-1, IL-6, tumor necrosis factor- $\alpha$ (TNF- $\alpha$ ), and interferon-gamma (IFN- $\gamma$ ) lead to the reduction of eryhtrocyte age, disturbance on erythroid progenitor cell proliferation, and rising of cellular iron uptake and retention. ${ }^{18}$ Increasing cytokines will raise hepcidin, thus reduces intestinal iron absorption. ${ }^{18}$ IL-1 also activates macrophages, leading to the rise of serum iron uptake and iron reserve, but IL-6 affects negatively in iron reserve release to the blood. ${ }^{19}$ The reduction of erythropoiesis process caused stagnant or even reduced reticulocyte count in patients with chronic inflammatory anemia in this study. Level of RET-He in patients with chronic inflammatory anemia in this study also tended to be normal since iron reserve for erythropoiesis was not depleted. According to study conducted in 2011 among patients with rheumatoid arthritis, it was known that RETHe level among patients with chronic inflammatory anemia were significantly higher compared with patients with irondeficiency anemia. ${ }^{19}$

This study revealed that majority SLE patients were reproductive-aged woman and most of them were suffering anemia. Most common type of anemia found was irondeficiency anemia, followed by autoimmune hemolytic anemia and chronic inflammatory anemia. Most patients suffered from anemia were between 25-34 years old.

General characteristic seen in this study only revealed anemia in women since overall subjects were exclusive to women. Median age of participants was 29.5 years old, a reproductive age. This result was consistent to previous study stated that SLE was commonly found among reproductiveaged women. ${ }^{20}$ It might be influenced by high estrogen hormones level among reproductive aged women, leading into the raise of immune responses. ${ }^{21}$

Most patients with anemia and patients with lowest hemoglobin level were aged between 25-34 years old. Anemia on SLE patients in reproductive age may be caused by the SLE itself, or other additional factors such as menstruation, high parity, or low socioeconomic level. ${ }^{22,23}$

Reproductive-aged women needs more iron intake due to menstrual bleeding and preparation of pregnancy. Women experience the rise of blood volume during pregnancy, around $40-45 \%$, in order to fulfill the needs of angiogenesis in enlarging uterus, the needs of fetal and maternal if venous return disturbance were occurred, and to reserve blood if bleeding was happened during the parturition. ${ }^{24}$ Iron is vital for fetal brain development especially during the first trimester. Iron deficiency anemia during pregnancy may lead 
into mental growth retardation of the children ${ }^{7}$ Iron deficiency anemia during pregnancy also raise the risk of preterm birth. ${ }^{25}$ Moreover, pregnancy on SLE patients may raise the disease activity. ${ }^{26}$ Anemia in SLE patients during pregnancy may cause by the progression of disease. However, distinguish it with anemia in normal women during pregnancy is difficult. ${ }^{27}$ The rise of disease activity may threat maternal and fetal safety which lead to an abortion. ${ }^{20,28}$ Thus finding the etiology of each anemia is important, so anemia can be treated appropriately.

Lacking of samples limited this study. Minimal samples with $95 \%$ interval confidence was 96 patients, while in this study, only 74 patients participated as research subjects, $90 \%$ of predicted samples. Other limitation was inability to detect the mixed of chronic inflammatory anemia and iron-deficiency anemia since RET-He parameter was weak to distinguished both type of anemia. ${ }^{28}$ We did not record the socioeconomic level, parity and other causes of anemia, so we could not concluded any the other factors causing anemia in this study.

We suggest to perform further study with higher number of subjects thus the portray of SLE patients will be more accurate. The use of other parameter such as ferritin, inflammation test, and better therapy documentation given to the patients will also enhance the more accurate results.

\section{Conclusion}

It is concluded that almost half of patients with SLE in Dr. Hasan Sadikin General Hospital Bandung year of 2016 was suffering from anemia. Anemia in SLE was more commonly found among patients aged between 25-34 years old. According to the parameter of RET-He and reticulocyte count, iron deficiency anemia is the most common type of anemia found, followed by autoimmune hemolytic anemia and chronic inflammatory anemia. Parameter of RET-He may not able to distinguish etiology of anemia on SLE patients by itself, and needs the addition of other parameters.

\section{Reference}

1. Keeling D., Isenberg D. Haematological manifestations of systemic lupus erythematosus. Blood Rev. 1993;7(4):199-207.

2. Hernandez D M, C CR, C MM, et al. Active haematological manifestations of systemic lupus erythematosus lupus are associated with a high rate of in-hospital mortality. SAGE J. 2016;45:1-6.

3. Bashal F. Hematological disorders in patients with systemic lupus erythematosus. Open Rheumatol J. 2013;7:87-95.

4. Voulgarelis M, Kokori SI, Ioannidis JP, et al. Anaemia in systemic lupus erythematosus: aetiological profile and the role of erythropoietin. Ann Rheum Dis. 2000;59(3):217-22.

5. Huu C, Le H. The prevalence of anemia and moderate- severe anemia in the us population. Plosone. 2016;11(11):1-14.

6. Allen LH. Anemia and iron deficiency : effects on pregnancy outcome. Am J Clin Nutr. 2000;71:1280-1284.

7. Zeng $L$, Brouwer D, Kok FJ, Yan H. Effect of iron deficiency anemia in pregnancy on child mental development in rural China. Pediatr Off $\mathrm{J}$ Am Acad Pediatr. 2013;131(3):755-763.

8. Olthof AW, Sijens PE, Kreeftenberg HG, et al. Correlation between serum ferritin levels and liver iron concentration determined by MR imaging: impact of hematologic disease and inflammation. Elsevier. 2007;25(3):228-31.
9. Brugnara C, Schiller B, Moran J. Reticulocyte hemoglobin equivalent (ret he) and assessment of iron-deficient states. Clin Lab Haematol. 2006;28(5):303-308.

10. Harmening DM. The red blood cell: struture and function. In: Harmening DM, editor. Clinical hematology and fundamentals od hemostasis. 5th ed. Maryland: F.A. Davis; 2009. 64-81 p.

11. Pedreira CE, Costa ES, Lecrevisse 0, Dongen JJM Van. Overview of clinical flow cytometry data analysis: recent advances and future challenges. Trends Biotechnol. 2013;31(7):415-25.

12. Oehadian A. Hematological problems in lupus erythematosus systemic[Kelainan darah pada lupus eritematosus sistemik].In: Oehadian A. Lupus Erythematosus Systemic Symposium for General [Simposium Lupus Eritematosus Sistemik untuk Awam]; Bandung: 2008, p. 2-6.

13. Janoudi N, Bardisi ES. Haematological manifestations in systemic lupus erythematosus. In: H. Almoallim, editor. Systemic Lupus Erythematosus. 1st ed. Rijeka: In Tech; 2012. 363-382 p.

14. Oamar K, Saboor M, Qudsia F, et al. Malabsorption of iron as cause of iron deficiency anemia in postmenopausal women. Pakistan J Med Sci. 2015;31(2):304-308

15. Peerschke EIB, Pessin MS, Maslak P. Using the hemoglobin content of reticulocytes (ret-he) to evaluate anemia in patients with cancer. Am J Clin Pathol. 2014;142:506-512.

16. Joosten E, Lioen P, Brusselmans C, Indevuyst C, Boeckx N. Analysis of the reticulocyte haemoglobin equivalent a useful test fo the diagnosis of iron deficiency anemia in geriatric patients. Eur $\mathrm{J}$ Intern Med. 2013;24(1):63-66.

17. Zhu A, Kaneshiro M, Kaunitz JD. Evaluation and treatment of iron deficiency anemia: a gastroenterological perspective. Dig Dis Sci. 2010;55:548-559

18. Ana Beatriz Barbosa Torino, Gilberti M de FP, Costa E da, Lima GAF de, Grotto HZW. Evaluation of erythrocyte and reticulocyte parameters as indicative of iron deficiency in patients with anemia of chronic disease. Rev Bras Hematol Hemoter.2015;37(2):77-81

19. Santen S Van, Dongen-lases EC Van, Vegt F De, et al. Hepcidin and hemoglobin content parameters in the diagnosis of iron deficiency in rheumatoid arthritis patients with anemia. Arthritis Rheum. 2011;63(12):3672-3680.

20. Kasjmir YI, Handono K, Wijaya LK, et al. Rekomendasi Perhimpunan Reumatologi Indonesia untuk diagnosis dan pengelolaan lupus eritematosus sistemik. Perhimpunan Reumatologi Indonesia; 2011.

21 Hahn BH. Systemic lupus Erythematosus. In: Harrison T, Resnick W, Wintrobe M,et al, editors. Harrison's principles of internal medicine.17th ed. Mcgraw-hill; 2008. 2075-2079.

22. K Pala, D Nundar. Prevalence and risk factors of anemia among women of reproductive age in Bursa, Turkey. Indian J Med Res. 2008;128(3):282286.

23. Cunningham FG, Leveno KJ, Bloom SL, et al. Maternal physiology. In: Twickler D, Wendel G, Dashe J, et al, editors. Williams obstetrics. 23th ed. New York: McGraw-Hill Education; 2010. 107-135 p.

24. Sadeghlan M, Fatourechi A, Lesanpezeshki M, Ahmadnezhad E. Prevalence of Anemia and Correlated Age Women in Rural Areas of Tabas. Journal of Family and Reproductive Health. 2013;7(3):139-144.

25. Banhidy F, Acs N, Puho EH, Czeizel AE. Iron deficiency anemia : pregnancy outcomes with or without iron supplementation. Nutr J. 2011;27:65-72.

26. Clowse MEB, Jamison $M$, Myers $E$, James $A H$. A national study of the complications of lupus in pregnancy. Am $\mathrm{J}$ Obstet Gynecol. 2008;127(August):1-6.

27. Baer AN, Witter FR, Petri M. Lupus and pregnancy. Obstet Gynecol Surv. 2011;66(10):639-653.

28. Clowse MEB. Lupus activity in pregnancy. Rheum Dis Clin North Am. 2007;33(5):237-252.

29. Wong $C$, Chen $T$, Lee $C$, Lin $C$, Chen $C$. Outcome of pregnancy in patients with systemic lupus erythematosus. Taiwan J Obstet Gynecol. 2006;45(2):120-123. 